\title{
Urgent surgical management for embolized occluder devices in childhood: single center experience
}

\author{
Gokhan Gokaslan ${ }^{*}$, Hasim Ustunsoy ${ }^{1}$, Hayati Deniz ${ }^{1}$ Ozerdem Ozcaliskan', Alptekin Yasim¹, Osman Baspinar² \\ and Gokalp Guzel ${ }^{1}$
}

\begin{abstract}
Background: In this study, we sought to analyze our experience in urgent surgical management for embolized cardiac septal and ductal occluder devices resulting from trans-catheter closure of atrial septal defect, ventricular septal defect and patent ductus arteriosus in childhood patient group.

Methods: We retrospectively reviewed 9 patients (aged 2-15 years) who underwent urgent surgery due to cardiac septal and ductal occluder embolization between January 2007 and December 2010. Congenital defects were atrial septal defect $(n=6)$, ventricular septal defect $(n=1)$, and patent ductus arteriosus $(n=2)$. Risk factors for device embolization and urgent surgical management techniques for embolized device removal were discussed.

Results: Removal of embolized devices in all cases and repair of damaged tricuspid valve in 2 patients were performed. Inevitably, all congenital defects were closed or ligated up to the primary defect. Total circulator arrest necessitated in 1 patient with ascending aortic device embolization. All operations were completed successfully and no hospital mortality or morbidity was encountered.

Conclusions: Although closure of left to right shunting defects by percutaneous occluder devices has a lot of advantages, device embolization is still a major complication. If embolized device retrieval fails with percutaneous intervention attempts, surgical management is the only method to remove embolized devices. In this circumstance, to provide an uneventful perioperative course, urgent management strategies should be well planned.
\end{abstract}

Keywords: Device embolization, Septal defect, Cardiac surgery

\section{Background}

Congenital heart diseases such as atrial septal defect (ASD), ventricular septal defect (VSD) and patent ductus arteriosus (PDA) are common type of childhood cardiac defects with an incidence of approximately 1 in 100 live births [1]. Surgical repair of all these defects was method of choice, until King et al. performed the first transcatheter closure of ASD [2]. Reported series with percutaneous deployment of occluder devices emphasize that trans-catheter closure technique avoids open-heart surgery and its associated complications. However, these interventional procedures are accompanied with their

\footnotetext{
*Correspondence: cerrah06@yahoo.com

'Department of Cardiovascular Surgery, Gaziantep University Medical Faculty, Gaziantep, Sehitkamil 27310, Turkey

Full list of author information is available at the end of the article
}

own major complications such as device embolization. In surgical literature, management of embolized devices was discussed in case reports and recently a multicenter experience was reported [3]. There is still lack of surgical management strategies for embolized devices in childhood and in this study we aimed to share our experiences.

\section{Methods}

The study was approved by the ethics committee of our institution, and because of its retrospective nature, patient consent was waived. This study is a review of 9 childhood patients who were urgently operated due to embolized cardiac septal and ductal occluder devices between January 2007 and December 2010 in our clinic. Preoperative and perioperative records of urgently

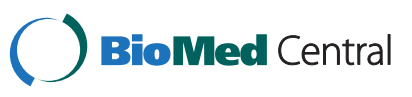




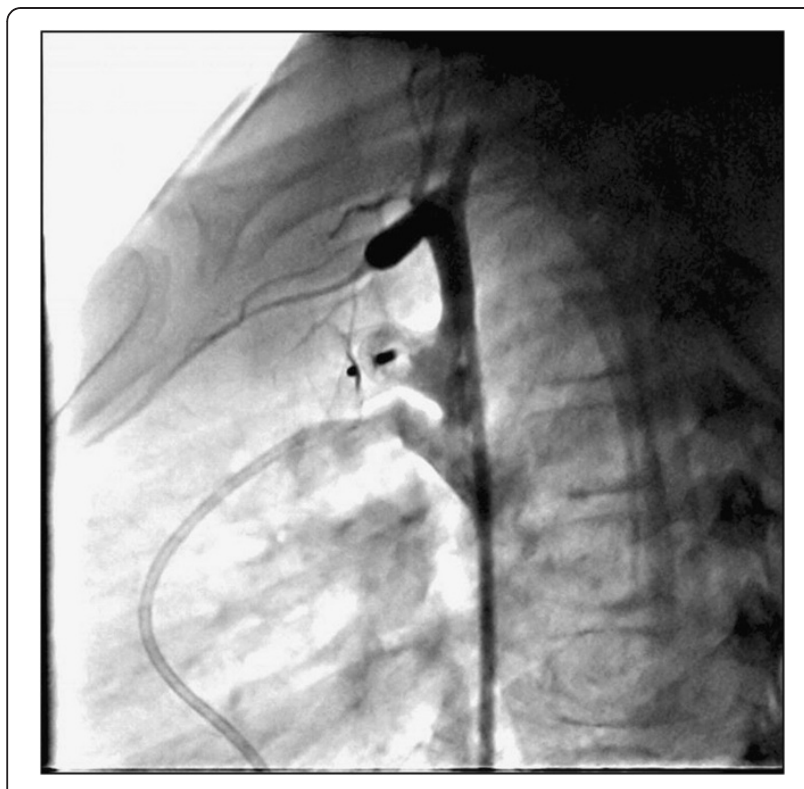

Figure 1 Embolised Amplatzer ${ }^{\circledR}$ ductal occluder in ascending aorta.

operated 9 patients were reviewed. Each patient is defined with a number. Adult patients, patients with late device complications and uneventfully retrieved devices by percutaneous interventions were excluded.

\section{Statistical analysis}

Data are expressed as absolute values, percentages, or mean \pm SD where appropriate.

\section{Results}

Between January 2007 and December 2010, 656 childhood patients (265 with ASD, 354 with PDA and 37 with VSD) underwent percutaneous closure of their defect at our institution. Device embolization requiring urgent surgical management occurred in 9 patients with a rate of $2.2 \%, 1.7 \%$ and $0.5 \%$ for ASD, VSD and PDA, respectively. Mean age was $8.8 \pm 4.3$ years, and six of 9 patients were female (66.6\%).
Majority of the primary defects were ASD (6 patients) with a diameter equal or grater than $10 \mathrm{~mm}$ and closure device waist sizes were ranging $19-28 \mathrm{~mm}$. Mean left to right shunt ratio $(\mathrm{Qp} / \mathrm{Qs})$ in patients with $\mathrm{ASD}$ was $4.9 \pm 3.3$ (range, 1.5-11) and rim tissue around the defects was $\geq 5 \mathrm{~mm}$ in echocardiography before transcatheter closure. However, aortic rim in two patients and inferior caval rim in one patient were found to be just a thin membrane in intraoperative examination. In another patient (patient number \#5) who was reported to have two ASDs in echocardiography, a large single ASD divided transversely with a thin band was observed intraoperatively. In remaining two patients with ASD, device embolization was due to the learning curve of the operator.

Defects were PDA in 2 patients. Systolic gradient between aorta and pulmonary artery over PDA was $8 \mathrm{mmHg}$ in patient \#7 which was found low because of the concomitant ASD and $112 \mathrm{mmHg}$ in patient \#8 with solely PDA. Thus, the occluder device was embolized and stuck in ascending aorta in patient \#7 during interventional procedure (Figure 1). Pulmonary artery embolization occurred in patient \#8 just after implantation of the device and it was tangled with tricuspid valve during percutaneous retrieval (Figure 2). In patient \#9 with VSD, systolic gradient between right and left ventricle was $61 \mathrm{mmHg}$. The occluder device was tangled with chordae tendineae of tricuspid valve while delivering it (Figure 3).

Timing of events, embolization sites, embolized devices and their sizes are presented for each case in Table 1. Surgery decisions were made after failure of percutaneous attempts to retrieve embolized devices. Although all patients were heparinized during catheter intervention, six patients were additionally heparinized with $100 \mathrm{U} / \mathrm{kg}$ heparin because activated coagulation time (ACT) was under 180 seconds, in order to prevent clot formation over device during surgical preparation and transfer to the operation room. Transesophageal echocardiography (TEE) was performed in all patients
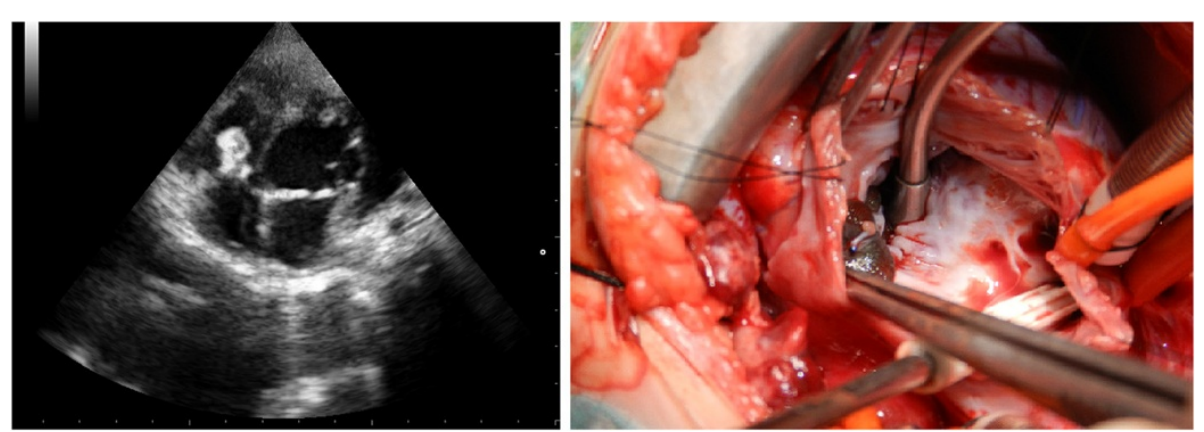

Figure 2 Echocardiographic and surgical views of embolised Amplatzer ${ }^{\circledR}$ ductal occluder. Device was tangled with tricuspid valve anterior leaflet chordas. Please note the ruptured chorda on the device which occurred during percutaneous retrieval attempts. 


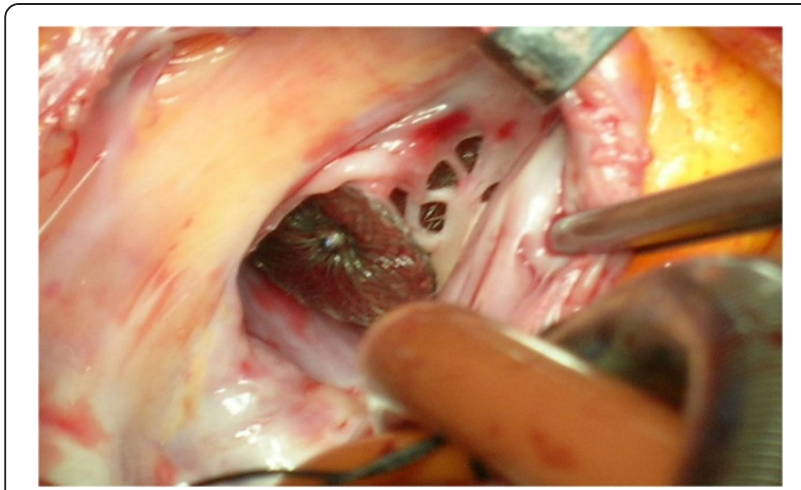

Figure 3 Embolised Amplatzer ${ }^{\circledR}$ septal occluder tangled with tricuspid valve and chordas.

intraoperatively. All surgical procedures were performed through median sternotomy. Aortic cannulation, selective vena cava superior and vena cava inferior cannulations were achieved. PDA was ligated in two patients just prior to initiation of cardiopulmonary bypass (CPB). An aortic cross-clamp (CC) was applied and antegrade cold cardioplegia was administered into the aortic root to achieve prompt diastolic cardiac arrest, except one patient with ascending aortic device embolization. Snaring of both vena cava superior and inferior, right atriotomy was performed. All embolized devices were easily removed directly or by folding two opposite edges of the device via forceps even it was stuck in the annulus of the valves or fell into the left ventricle (Figure 4). Following removal of embolized devices, tricuspid septal leaflet chordae damaged in 2 patients reattached to the septal leaflet and commissure damaged in one patient was repaired with prolene suture. According to the size of the defects, ASD and VSD closures were performed directly or using a pericardial patch manner.

In patient with ascendant aortic embolization (patient \#7 with PDA and concomitant ASD), device position was confirmed with TEE following initiation of $\mathrm{CPB}$ and patient was cooled to 20 degree Celsius. Thereafter distal

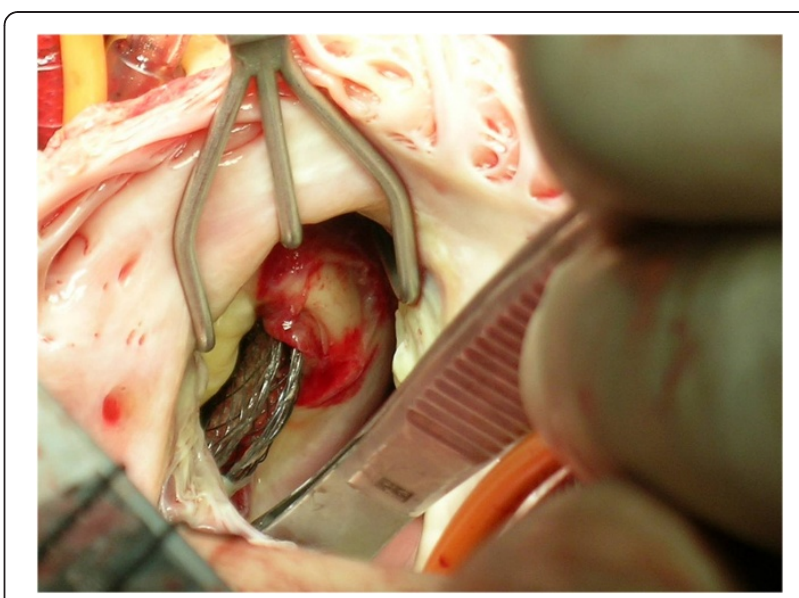

Figure 4 Embolised Amplatzer ${ }^{\circledR}$ septal occluder stuck in the annulus of the pulmonary valve.

ascending aortotomy was performed just left lateral side of the aortic cannula via total circulator arrest (TCA) of 6 minutes. Embolized device was removed and aortotomy was closed in two layers. While heating the patient, direct closure of additional secundum ASD was performed through the right atriotomy. In early postoperative echocardiography, systolic pulmonary artery pressure was shown decreased from 82 to $45 \mathrm{mmHg}$. Surgical management data are presented for each patient in Table 2.

The mean time interval between decision of the surgical removal of the embolised device and surgical treatment was $65 \pm 16.5$ (range, 40-90) minutes. Mean blood transfusion was $1.88 \pm 0.64$ units. Mean duration of intensive care unite stay was $1.2 \pm 0.44$ days and mean total hospital stay was $4.9 \pm 1.3$ days. Any tromboembolism or peripheral artery complication including ischemia was not observed postoperatively. No mortality or surgical complication was encountered during hospital stay. The mean follow-up period was $37.8 \pm 17.1$ months. All patients were free of cardiac symptoms and

Table 1 Characteristics of patients and embolized devices

\begin{tabular}{|c|c|c|c|c|c|c|c|c|}
\hline $\begin{array}{l}\text { Case } \\
\text { No: }\end{array}$ & $\begin{array}{l}\text { Age } \\
\text { (Years) }\end{array}$ & $\begin{array}{l}\text { Primary } \\
\text { disease }\end{array}$ & $\begin{array}{l}\text { BSA } \\
\left(\mathrm{m}^{2}\right)\end{array}$ & $\begin{array}{l}\text { Defect size } \\
\quad(\mathrm{mm})\end{array}$ & $\begin{array}{l}\text { Qp/ } \\
\text { Qs }\end{array}$ & $\begin{array}{l}\text { Embolized device and size } \\
\qquad(\mathrm{mm})\end{array}$ & $\begin{array}{l}\text { Embolization } \\
\text { site }\end{array}$ & $\begin{array}{l}\text { Timing of } \\
\text { event }\end{array}$ \\
\hline 1 & 4 & ASD & 0.66 & 20 & 6.08 & Amplatzer ${ }^{\circledR}$ 9-PFO-024(38-34) & Tricuspid valve & 1 day \\
\hline 2 & 8 & ASD & 0.84 & 19 & 5 & Amplatzer ${ }^{\circledR}$ 9-PFO-022(32-36) & Right ventricle & 1 day \\
\hline 3 & 9 & ASD & 0.9 & 22 & 11 & Amplatzer ${ }^{\circledR}$ 9-PFO-026(36-40) & Left ventricle & Peroperative \\
\hline 4 & 15 & ASD & 1.26 & 27 & 3.5 & Amplatzer ${ }^{\circledR}$ 9-PFO-019(29-33) & Pulmonary valve & 1 day \\
\hline 5 & 15 & ASD & 1.57 & $27-28$ & 4 & Amplatzer ${ }^{\circledR}$ 9-PFO-028(38-42) & Right atrium & Peroperative \\
\hline 6 & 9 & ASD & 1.08 & 10 & 1.5 & Biostar BSR-28 & Tricuspid valve & 2 days \\
\hline 7 & 8 & PDA & 0.81 & 4.5 & 1.4 & Amplatzer ${ }^{\circledR}$ 9-PDA006(10-8) & Ascending Aorta & Peroperative \\
\hline 8 & 2 & PDA & 0.45 & 4.55 & 3.1 & Amplatzer ${ }^{\circledR}$ Nit.Ocluder(9-6) & Tricuspid valve & Peroperative \\
\hline 9 & 10 & mVSD & 0.79 & 7 & 2.2 & Amplatzer $^{\circledR}$ 9-VSDmusc-008(16) & Tricuspid Valve & Peroperative \\
\hline
\end{tabular}

ASD: Atrial septal defect, mVSD: Muscular ventricular septal defect, PDA: Patent ductus arteriosus, Qp/Qs: Left to right shunt ratio. 
Table 2 Surgical management data

\begin{tabular}{|c|c|c|c|c|c|c|}
\hline \multirow{2}{*}{$\begin{array}{l}\text { Case } \\
\text { No: }\end{array}$} & \multirow{2}{*}{$\begin{array}{l}\text { Age } \\
\text { (Years) }\end{array}$} & \multirow{2}{*}{$\begin{array}{l}\text { Primary } \\
\text { disease }\end{array}$} & \multirow{2}{*}{$\frac{\text { TCA }}{\text { (Minute) }}$} & \multirow{2}{*}{$\frac{C C}{\text { (Minute) }}$} & \multirow{2}{*}{$\frac{\mathrm{CPB}}{\text { (Minute) }}$} & \multirow[t]{2}{*}{ Surgical management } \\
\hline & & & & & & \\
\hline 1 & 4 & ASD & - & 28 & 44 & ASO removal and ASD pr. \\
\hline 2 & 8 & ASD & - & 37 & 45 & ASO removal and ASD rpp. \\
\hline 3 & 9 & ASD & - & 18 & 30 & ASO removal and ASD pr. \\
\hline 4 & 15 & ASD & - & 30 & 45 & ASO removal and ASD rpp. \\
\hline 5 & 15 & ASD & - & 28 & 37 & ASO removal and ASD rpp. \\
\hline 6 & 9 & ASD & - & 33 & 42 & $\begin{array}{l}\text { ASO removal, Tricuspid valve septal leaflet chorda and posterior leaflet septal } \\
\text { commissure repair, ASD rpp }\end{array}$ \\
\hline 7 & 8 & PDA & 6 & 0 & 116 & PDA ligation, Coil removal via aortotomy with TCA and ASD pr. \\
\hline 8 & 2 & PDA & - & 30 & 42 & PDA ligation, Tricuspid valve septal leaflet corda repair \\
\hline 9 & 10 & mVSD & - & 182 & 214 & VSO removal, 2 small muscular and $1 \mathrm{~cm}$ inlet VSD rpp \\
\hline Mean & & & & $\begin{array}{c}42.8 \pm \\
53.3\end{array}$ & $\begin{array}{c}68.3 \pm \\
60.2\end{array}$ & \\
\hline
\end{tabular}

ASD: Atrial septal defect, ASO: Atrial septal occluder, CC: Cross clamp time, CPB: Total cardiopulmonary bypass time, $m V S D$ : Muscular ventricular septal defect, PDA: Patent ductus arteriosus, pr: Primer repair, Qp/Qs: Mean left to right shunt ratio, rpp: repair with pericardial patch, TCA: Total circulatory arrest time, VSO: Ventricle septal occluder.

there was no residual defect in their one-year and last follow-up. In two patients with tricuspid valve repair, mild regurgitation was reported in their last follow up echocardiography.

\section{Discussion}

Interventional trans-catheter closure for all types of cardiac defects with left to right shunting gained wide popularity and became a standard technique against surgery for nearly two decades all over the world. Recent studies including both adult and childhood patients emphasizes that trans-catheter closure is a safe method with shorter hospital stay, less mortality and morbidity rates. Moreover, it also obviates surgical risk factors and inevitable operation scar of surgery [4-7]. However, this procedure is not free of complications. Embolization of the device may occur in unexpected sites of circulatory system and may cause serious damages. In the literature, embolization rates were reported $4 \%$ in 1991 [8], 20\% in 1996 [9], and dramatically decreased to $0.55 \%$ in 2005 with new generation devices [10]. In a review reported in 1996, suggested mechanisms for acute failure were operator related factors resulting from inadequate experience (learning curve), inaccurate deployment, inadequate defect rim to hold the device, tearing of the interatrial septum especially at the lower rim of the ASD owing to catheter and device manipulations and Sideris buttoned device itself [11]. Berdat et al. reviewed their surgical experiences with embolized Sideris and ASDOS devices and suggested that new generation Amplatzer ${ }^{\circledR}$ devices indicated more promising results [12]. Despite new generation occluder devices were developed, embolized devices which require surgical management are still reported and majority of these are case reports [13-15]. In a recent multi-center study which investigates device embolization complications, 3 patients died of stroke due to cerebral embolism and cardiac perforation was noted in one patient. The authors concluded that 'Once a complication leading to surgery occurs, mortality is significantly greater than that of primary surgical ASD closure' [3].

In our study majority of primary defects were ASD and embolization rate was $2.2 \%$. Patient selection for ASD closure with occluder device is generally performed according to the sizes of the defect and rim. Misra et al. reported their experience with defective aortic rim which caused device embolization to pulmonary artery and they emphasized the importance of the aortic rim in device deployement [16]. If rim thickness is weak or just a membrane, this may lead device embolization. In our study, aortic rim in two patients and inferior cava rim in one patient were a thin membrane. Additionally, in patient \# 5 who was thought to have two ASDs in echocardiography, intraoperative investigation revealed that there existed actually one large ASD divided by a thin band. Combination of thin rim and high Qp/Qs might have been responsible for the embolization in these patients. Moreover, during the percutaneous retrieval attempts, intracardiac structure damage may occur particularly at valvular and subvalvular apparatus. Within our experience, tricuspid septal leaflet chordae injury in two cases and posterior leaflet septal commissure damage in one case were encountered during operations. These injuries were repaired successfully.

Device embolization rate during trans-catheter PDA occlusion was reported as $0.5 \%$ in a multi-center study [17]. Successful surgical removal of embolized PDA devices from pulmonary arteries and descending aorta were reported formerly $[13,14]$. Magee et al. suggests that embolization of the PDA device more commonly 
occurs in the pulmonary circulation than the systemic circulation because of the pressure gradient [18]. We encountered with embolized PDA devices in two cases (patient \#7 and \#8). PDA diameters were 4.5 and $4.55 \mathrm{~mm}$. Although ductal diameters were small, gradients between aorta and pulmonary artery were the reason for the device embolization. In patient \#7 with concomitant ASD, PDA occluder device dislodged and migrated to ascending aorta due to high pulmonary pressure. In patient \#8, gradient was $112 \mathrm{mmHg}$ and device was embolized to pulmonary artery. Although PDA diameters were similar, the gradient in these cases determined the dislodgement of the device and the embolization site.

Holzer et al. reported device embolization rate of $2.7 \%$ in muscular VSD closure in both adult and childhood patients [19]. In 2007, device embolization rate was reported as $0.9 \%$ for the European registry of Amplatzer ${ }^{\circledR}$ VSD occluder [6]. In a review reported in 2010, the author emphasizes TEE guidance in transcatheter device closure of muscular VSD [20]. In our data, device embolization occurred in one patient (patient \#9) with muscular VSD. Device was tangled with tricuspid valve chordae during deployment probably because of the lack of TEE guidance.

Device removal was performed through the right atrium in our $8 / 9$ patients. Performing right atriotomy provided us a good surgical exposure to reach all intracardiac structures even to the left ventricle via ASD. Devices even stuck to the valvular annulus were removed easily via folding their edges with forceps. Intracardiac structure damages which possibly occurred due to percutaneous device retrieving attempts at valvular and subvalvular apparatus were repaired successfully. Only one of the devices which was embolized to the ascending aorta was removed via TCA after confirming its position with TEE. Perioperative TEE guidance is essential particularly in these patients, because the device migration might occur after aortic cannulation and initiation of CPB [15].

In post operative period, fortunately we did not encounter any embolism, tamponade or arrhythmias. The reasons for no death or uneventful course in our operations may be related to stand-by cardiac surgical team,

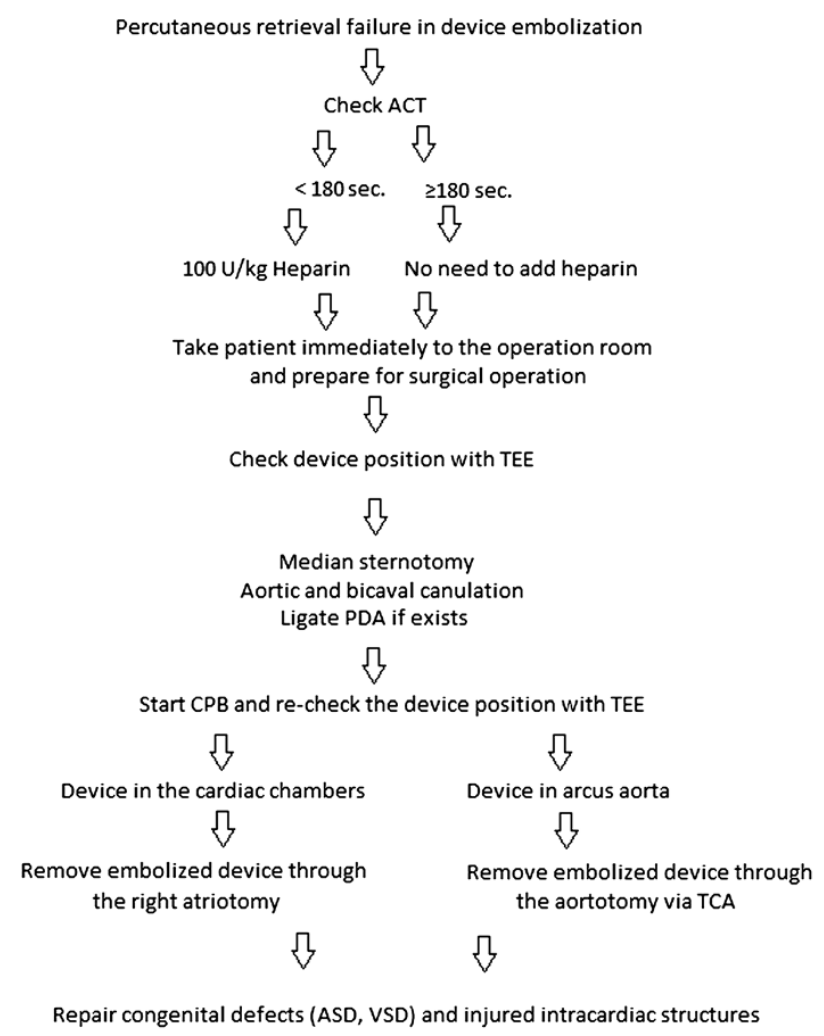

ACT: Activated coagulation time; ASD: Atrial septal defect; CPB: Cardiopulmonary bypass; PDA: Patent ductus arteriosus; TCA: Total circulatory arrest; TEE: Transesophageal echocardiography; VSD: Ventricular septal defect

Figure $5 \mathrm{~A}$ possible algorithm for surgical management of complicated embolized devices. 
additional heparinization of the patients after the onset of embolization, appropriate surgical management strategy. An algorithm may be suggested considering our limited experiences together with the results of the literature for a more helpful surgical management strategy. A possible algorithm is indicated in Figure 5.

\section{Conclusions}

Occluding of left to right shunting defects by devices is less invasive than surgery. Echocardiographic evaluation of rim quality and measurement of the gradients may help choose the appropriate patients for interventional procedures. During the intervention, TEE guidance is needed to confirm the echocardiographic findings and support the deployment procedures. Despite all, embolization is still a major complication in interventional closure of the defects. If percutaneous catheter retrieval attempts fail, surgical management is the only method to remove the embolized devices. However, an urgent surgery in a patient who already had many hours of anesthesia perhaps with compromised hemodynamics due to blood loss and/or damaged intra cardiac structures is supposed to have more intraoperative or postoperative complications than an elective surgical repair of the primary lesion. Our experiences without any serious complication may be attributed to the appropriate surgical management strategy.

Competing interests

The authors declare that they have no competing interests.

\section{Authors' contributions}

GG and UH carried out the study design and drafted the manuscript, $\mathrm{DH}$, $\mathrm{OO}$ and GG collected patients' data, YA and BO participated in the design of the study. All authors read and approved the final manuscript.

\section{Author details}

${ }^{1}$ Department of Cardiovascular Surgery, Gaziantep University Medical Faculty, Gaziantep, Sehitkamil 27310, Turkey. ${ }^{2}$ Department of Pediatric Cardiology, Gaziantep University Medical Faculty, Gaziantep, Turkey.

Received: 13 August 2012 Accepted: 4 December 2012

Published: 7 December 2012

\section{References}

1. Hoffman JIE: Incidence of congenital heart disease: I. Postnatalincidence. Pediatr Cardiol 1995, 16:103-13.

2. King TD, Thompson SL, Steiner C, Mills NL: Secundum atrial septal defect. Nonoperative closure during cardiac catheterization. JAMA 1976, 235(23):2506-9.

3. Sarris GE, Kirvassilis G, Zavaropoulos $P$, et al: Surgery for complications of trans-catheter closure of atrial septal defects: a multi-institutional study from the European congenital heart surgeons association. Eur $J$ Cardiothorac Surg 2010, 37(6):1285-90.

4. Bialkowski J, Karwot B, Szkutnik M, Banaszak P, Kusa J, Skalski J: Closure of atrial septal defects in children: surgery versus Amplatzer device implantation. J Tex Heart Inst J. 2004, 31(3):220-3.

5. Suchon E, Pieculewicz M, Tracz W, Przewlocki T, Sadowski J, Podolec P: Transcatheter closure as an alternative and equivalent method to the surgical treatment of atrial septal defect in adults: comparison of early and late results. Med Sci Monit 2009, 15(12):CR612-7.
6. Carminati M, Butera G, Chessa M, et al: Transcatheter closure of congenital ventricular septal defects: results of the European Registry. Eur Heart $J$ 2007, 28(19):2361-8.

7. Du ZD, Hijazi ZM, Kleinman CS, Silverman NH, Larntz K: Comparison between transcatheter and surgical closure of secundum atrial septal defect in children and adults: results of a multicenter nonrandomized trial. J Am Coll Cardiol 2002, 39(11):1836-44.

8. Latson LA, Benson LN, Hellenbrand WF, Mullins CE, Lock JF: Transcatheter closure of ASD_early results of multi-center trial of the Bard clamshell septal occluder. Circulation 1991, 84(Suppl):II-44.

9. Am W, Rey C, Bourlon F, et al: French experience in the closure of atrial septal defects of ostium secundum type with the Sideris button occluder. Arch Mal Coeur Vaiss 1996, 89:509-15.

10. Tan CA, Levi DS, Moore JW: Embolization and transcatheter retrieval of coils and devices. Pediatr Cardiol 2005, 26(3):267-74

11. Agarwal SK, Ghosh P, Mittal P: Failure of devices used for closure of atria septal defects: mechanisms and management. J Thorac CardiovascSurg. 1996, 112:21-6.

12. Berdat PA, Chatterjee T, Pfammatter JP, Windecker S, Meier B, Carrel T: Surgical management of complications after transcatheter closure of an atrial septal defect or patent foramen ovale. J Thorac Cardiovasc Surg 2000, 120(6):1034-9.

13. Shahabuddin S, Atiq M, Hamid M, Amanullah M: Surgical removal of an embolised patent ductus arteriosus amplatzer occluding device in a 4-year-old girl. Interact Cardiovasc Thorac Surg 2007, 6(4):572-3.

14. McMullan DM, Moulick A, Jonas RA: Late embolization of Amplatzer patent ductus arteriosus occlusion device with thoracic aorta embedment. Ann Thorac Surg 2007, 83(3):1177-9.

15. Luqman Z, Ansar J, Ullah H, Amanullah M: Retrograde aortic perfusion dislodges a dislodged Amplatzer device. J Thoracic Cardiovasc Surg. 2008, 135:698-699.

16. Misra M, Sadiq A, Namboodiri N, Karunakaran J: The 'aortic rim" recount: embolization of interatrial septal occluder into the main pulmonary artery bifurcation after atrial septal defect closure. Interact Cardiovasc Thorac Surg 2007, 6(3):384-6.

17. Pass RH, Hijazi Z, Hsu DT, et al: Multicenter USA Amplatzer patent ductus arteriosus occlusion device trial. J Am Coll Cardiol 2004, 44:513-519.

18. Magee AG, Huggon IC, Seed PT, Qureshi SA, Tynan M: Transcatheter coil occlusion of the arterial duct. Results of the European registry. Eur Heart J 2001, 22:1817-1821.

19. Holzer R, Balzer D, Cao QL, Lock K, Hijazi ZM, Amplatzer Muscular Ventricular Septal Defect Investigators: Device closure of muscular ventricular septal defects using the Amplatzer muscular ventricular septal defect occluder: immediate and mid-term results of a U.S. registry. J Am Coll Cardiol 2004, 43(7):1257-63

20. Fu YC: Transcatheter device closure of muscular ventricular septal defect. Pediatr Neonatol 2011, 52(1):3-4.

doi:10.1186/1749-8090-7-127

Cite this article as: Gokaslan et al: Urgent surgical management for embolized occluder devices in childhood: single center experience. Journal of Cardiothoracic Surgery 2012 7:127

\section{Submit your next manuscript to BioMed Central and take full advantage of:}

- Convenient online submission

- Thorough peer review

- No space constraints or color figure charges

- Immediate publication on acceptance

- Inclusion in PubMed, CAS, Scopus and Google Scholar

- Research which is freely available for redistribution 